\title{
A Perspective of Food Access within the Developing World
}

\author{
Mohammad Taghi Sheykhi* \\ Department of Social Science, Alzahra University, Iran
}

*Corresponding author: Mohammad Taghi Sheykhi, Professor of Sociology, Department of Social Science, Alzahra University, Tehran, Iran, Email: mtshykhi@alzahra.ac.ir, mtshykhi@yahoo.com.

Received Date: December 03, 2018

Published Date: December 17, 2018

\begin{abstract}
The paper explores how food production and accessibility has become problematic within the developing nations. The problem will be more acute in the years to come due to boosting migrations from rural areas. Mismanagement of food distribution and processing is also counted as an issue. Modernization of agriculture could be recommended as a solution. Hunger and shortage of food have highly impacted the cities of developing countries to be unbearably densely populated. The UN has positively recommended that food problem within the developing world could be solved only if improved technologies are used. However, while more demands for food is observed today, more food needs to be produced. Similarly, as in urban areas more money is in circulation, people's lifestyle is ever changing demanding more food in quantity and quality. Sustainable agricultural revolution emphasizes on efforts to be made to ever raise yields to feed the increasing population. The paper points to the increasing number of world countries facing malnutrition creating challenges. They all need solutions and remedies.
\end{abstract}

Keywords: Purchasing power; Modernizing agriculture; Food security; Increasing demand; Multiple agricultural revolution

\section{Introduction}

Currently there is about one billion people suffering from chronic hunger mainly in the developing world. Based on the information received from $\mathrm{WHO}$ and $\mathrm{FAO}$, today, about one seventh of the world population is suffering from shortage of food items. Under the present circumstances the number of hungry people in Africa is increasing day by day. While Asia has been able to improve its food products due to more access to improved technologies, Africa with 56 countries is mainly in an unfavorable situation so far as their food productivity is concerned. Therefore, the less developed world needs more capital investment on agriculture and food products. While the world farmers produce enough food products, their products are not well distributed, and many people do not have the purchasing power to buy them. That is because prices are always inflating in those countries. In those countries the people have not the purchasing power to get the food items that they need. Such a scenario leaves many in under-nutrition, malnutrition and even hunger. The above situation is observed in many African countries and other parts of the developing world. The consequences of such an state is the unwanted and uncontrolled migrations followed by increasing urbanization; that is a state creating socio-economic insecurity for those countries. By the year 2050, two to three billion more people will be added to the world population, and in that stage, demand for food materials will be doubled. Therefore, from the economic sociology point of view, because of the increasing world population, more advanced technologies must be applied to produce more food. Therefore, sociologists and agricultural experts must always project the future population and food needs for the year 2050. If not, the future generations will likely face food crisis. As per projections, people in future will have higher incomes, and because of that, they will demand more food and services. Such a movement will lead to more economic dynamics. Therefore, countries need to make possible the grounds to produce, distribute and consume. In this way, and through suitable interactions between production and consumption, backgrounds of economic and welfare of societies are set. Improving and modernizing agriculture are known as one of the ways to solve/combat hunger. It is worth noting that agriculture must be of priority in planning projects by the governments of the developing countries. It is in this way that even the industrial sector could be improved and promoted. Unfortunately, in today's world a sum of one seventh of the world population is suffering from food shortage. 


\section{Method of Research}

Methodology used in the present article is of qualitative type. In that, various paradigms for finding facts have been used. Qualitative research usually studies the people in their natural settings. In finding facts for the research, the researcher engaged in careful data collection and thoughtful analysis of what was relevant. In the documentary research applied in the present article, printed and written materials were widely regarded. The research was performed as a qualitative library type in which the researcher had to refer to relevant and related sources. In the present research, various books on food were thoroughly investigated, and the needful inferences were made. The data fed by the investigator in the present research is dependable and reliable.

\section{Global hungry people}

According to FAO 2009, more than one billion people of the world mainly in the developing world is suffering from hunger. They are in countries with limited agricultural capacities; such countries do not have the necessary technologies for agriculture. The existing conditions contribute to increasing migrations from such countries Maharatna [1].

Paralleled with such conditions, food prices are constantly increasing. Such increasing prices are impoverishing the poor and the hungry more than others, i.e. a situation that makes the poor of the world poorer and poorer--losing their purchasing power every day. The above scenario is on the agenda of many world organizations including FAO. If the situation is not changed, a dark and insecure future is waiting for such people. If pessimism continues based on the fact that earth does not have the capability to feed its people, that would be a tragedy. Social, economic and geopolitical changes in the world in the past few decades in many stances have caused shortage of food, increasing prices and hunger, and that motivates some of the economic pessimists to declare that earth is not able to easily feed the hungry. But, in the meantime, some world organizations such as the UN have positively interfered, saying that through effective policies and more advanced technologies, shortage of food materials could be responded, and in that way poverty and hunger are minimized. The food and agricultural sector of the UN offers solutions and has a central role to eliminate hunger and poverty (UN) [2].

As projected, while the world population will reach 9.5 billion by the year 2050, more migrations from rural to urban areas are underway, pushing the countries towards shortage of food stuff and consequently rising prices. While suspension of food materials is underway, food consumption is also increasing due to more communications. Hence, economic sociologists need to pay special attention to the upcoming crisis. Under such a scenario, new proposals and plans must be implemented to create more food security within the developing world. While due to sociodemographic change, lifestyle and life expectancy are also changing, planners and researchers need to operationalize balanced programs to be able to respond the needs of the citizens. Nowadays, those developing countries that have proceeded regardless of projections, are facing increasing economic and social challenges. They are at the same time facing food shortages. Challenges caused by environmental limitations, shortage of farming lands, shortage of water resources, climate change etc. have all made food supply problematic. World food conference in 1996 defines food security as a condition in which there is food for all at any time; people would have access to enough safe food, and it is only in this way that they can have productive and safe life [3]. Currently, African countries are facing such challenges which will increase shortage of food and increasing hunger in those countries.

\section{Increasing demand}

As projected, demand for food will double by the year 2050 which is the result of population increase by that year. In fact food materials will not increase in that scale and that will create shortage and challenges. Change in consumption patterns, increasing literacy, urbanization and optimistically increasing income all will motivate people to more food demand. Therefore, economic sociologists are ever seeking policies, methods and strategies to use to decrease the crisis. It is only the developed countries under their economic, social and cultural conditions that could be excluded from the food crisis by the year 2050.Similarly, social networks are highly affecting food demand in the years to come. Social networks joining the people together, will motivate them to consume more food items Higgs [4].

\section{Past food productions}

Increase in food products occurred in the past due to agricultural (green) revolution which followed the industrial revolution. That somehow or the other ended starvation and food shortage. The above situation also led to economic growth for many; such a process contributed to economic growth of up to five times more for many countries. Such a supply of food products led to better health and eugenics for some in many countries. Agricultural revolution followed by industrial revolution contributed to the availability of more food in the market; increasing the quality of food items, leading to healthier generations Gibbons [5].

During the recent past years as more advanced technologies have been exploited in agriculture, the economies of many developing countries have transformed; they have been able to have better yields from their lands, and thereby they have been able to have more benefits and surplus values. Due to more international trade and sale of agricultural products, many developing countries have earned more GNP per capita, and in this way they have got more purchasing power. Such a transition has positively affected the citizens and placed them in higher quality of life. Therefore, to obtain higher income, countries need to sustain their agricultural revolution, and thereby keep a considerable number of their citizens active in agricultural sector. Such a process provides many nations with more guarantees such as food security, higher purchasing power etc. It must be noted that the industrial countries while giving the first priority to their industries, they also keep active and sustainable their agricultural sector. Despite the above facts, yields are not satisfactory in many parts of Africa and South Asia. In those areas people generally cannot exploit advanced technologies in agricultural sector. However, many people in Africa and South Asia are facing insecurity of food needs Pretty [6]. However, the world must prepare and promote its food products by 2050 with a world 
of over 9 billion people while there will be shortage of water and land as well Beddington [7].

\section{Multiple agricultural revolution}

This concept indicates efforts and focuses on increasing yields. Though the agricultural revolution occurred centuries back, since then because of population increase and change in lifestyle, countries have always been following increase of agricultural products; so that it would be possible to respond the nutrition needs of their people. In recent decades, through the application of modern technologies agricultural revolution has ever been strengthened and even reached many traditional societies. While during the 20th century world population quadrupled from 1.5 billion to 6 billion, countries would inevitably adopt more advanced policies to respond the newly-emerged nutrition needs of the people. Under the conditions of agricultural revolution periodical famines declined, or even eliminated within some nations. The agricultural revolution continued in this manner, and nations improved their production styles in scientific and specialized manners. Similarly, during the second agricultural revolution countries became more resistant against the environmental challenges, climate change, market fluctuations etc.

Therefore, during the past one hundred years that the second agricultural revolution happened, many countries could access more relevant advanced technologies, fertilizers, green house products and refrigeration to improve their mechanical productivity. The second agricultural revolution that made use of more facilities, improved and upgraded yields with special reference to the advanced countries Retrieved [8]. In this way, the quality and quantity of many agricultural products improved. Such a change improved the per capita food access; that is an indicator improving the quality of life of many communities. Such a change improved life expectancy of many nations for thirty years or more. Though the second agricultural revolution increased the global volume of food, yet there is still more than one billion hungry people in need of food in the world. As mentioned before, countries in Africa can escape hunger and poverty through exploiting more advanced technologies, education and mechanization of agriculture. In the meantime, international supports by WHO, UNESCO and FAO, each can bring about considerable changes in the economic and social sectors of the African countries. Similarly, exploitation of land and water resources must happen in a way that next generations could use them too. Over-exploitation of forests, underground resources etc. will endanger the life of the next generations. Therefore, exploitation of resources must take place in a balanced manner. It is worth noting that industrial countries use their resources with prediction, and in a precautionary manner, very different from Africa; they always project their next generations too.

\section{Food security}

Transition in food security is possible when investments can take place via public and private sectors. Privatization of many economic and agricultural sectors are currently taking place. Therefore, financial institutions such as banks must find the opportunity to invest in food industries. In this way, African countries will be able to experience some more growth in their food sectors. Not only the African continent, but many other developing countries are currently facing the food crisis. Private sector plays a determining role to provide food materials with special reference to the developing urban areas. Increasing patterns of urban consumption is generally responded by the private sector in various countries Dubbeling [9]. Similarly, access to sufficient food will be achieved only when the scientific, industrial, communications and educational infrastructures are provided. So, those countries that have not sufficient infrastructures, are suffering from shortage of food and poor agriculture; a process sometimes leading to famine for some people. Elimination of poverty and hunger also needs markets free of corruption and deviance. One of the difficulties of the developing countries is the commercial markets with corrupted agents and middlemen, and under such circumstances farmers do not earn the right benefits; they gradually leave farming and join the urban economy as laborers the economies that do not well welcome such workers. In the meantime, to reach their objectives of food security and prevent hunger, the relevant countries must be able to face the climate change. They should be able to obtain suitable strategies, technologies and other necessary means to face the new natural conditions. That is, the process which affects the economy of the countries in various forms. Governments need to plan and improve strategies to develop their food productions. Such a priority can create healthier generations that will positively affect next generations too. However, all the countries of the world, somehow or the other are under the impact of malnutrition and need to encounter it. Therefore, it seems to be the largest challenge of the world safety (WHO) [10].

\section{Conclusion}

So far as the developing countries are concerned, many of the food producers, and those producing agricultural products and food items, they are not well familiar with how to be make use of resources, producing agricultural, products, preservation of products and the like. Such a scenario contributes to food shortage in those countries. Therefore, dissipation of up to date information in the developing world needs to increase within the farmers and food producers as much as possible. Based on the real facts, hunger still includes one billion people of the world. After the passage of six decades since 1960, or the discoveries towards the green revolution, yet suffering from malnutrition, shortage of food and poverty are observed within a large number of people. Many people of the less developed world and Africa are suffering from daily short food rations, i.e. what brings about food calories. This situation affects not only the present generations, but the next generations as well. Therefore, governments must prioritize strengthening and developing their plans of food production. In this manner, countries could have healthier generations. However, during the present century that the world will experience plus 4 degree of heat, shortage of water and consequently food will be followed. The entire circumstances mentioned, will lead to food crisis.

\section{Acknowledgement}

None. 


\section{Conflict of Interest}

No Conflict of Interest.

\section{References}

1. Maharatna A (2016) Food Scarcity and Migration: An Overview, Social Research, UK.

2. (2017) UN Sustainable Development Goals, 17 Goals to Transform Our World.

3. (2005-2015) Water for Life, International Decade for Action Water for Life, UNDESA.

4. Higgs S, Jason T (2016) Social Influences on Eating, Current Behavioral Sciences, Elsevier 9: 1-6.
5. Gibbons SR (2012) In: The True Political Mothers of Today: Farm Women and the Organization of Eugenic Feminism in Alberta (Master of Arts Thesis), University of Saskatchewan, Saskatoon.

6. Pretty JN, James IM, Rachel EB (2003) Reducing Food Poverty by Increasing Agricultural Sustainability in Developing Countries, UK., Elsevier.

7. Beddington, J (2010) Food Security: Contributions from Science to a New and Greener Revolution, Philos Trans R Soc Lond B Biol Sci 365(1537): 61-71.

8. (2018) Retrieved Material.

9. Dubbeling M (2016) In: The Role of Private Sector in City Region Food Systems, Analysis Report, the Netherlands.

10. (2018) World Health Organization, Malnutrition, Switzerland. 